This is a peer-reviewed, accepted author manuscript of the following article: Adams, P., \& McLennan, C. (Accepted/In press). Towards initial teacher education quality: epistemological considerations. Educational Philosophy and Theory.

\title{
Towards Initial Teacher Education quality: epistemological considerations
}

\section{Paul Adams, University of Strathclyde \\ Carrie McLennan, University of Dundee \\ Towards Initial Teacher Education quality: epistemological considerations}

\begin{abstract}
Initial Teacher Education quality is often judged through the auspices of audit-style mechanisms designed to facilitate the identification of matters pertaining to the 'readiness' of student teachers to enter the world of the classroom as fully qualified. In this regard, quality of programmes is often determined by the knowledge and skills student teachers demonstrate. Whilst ontological aspects are not necessarily elided, they are often ignored in favour of such epistemological matters. While such knowledge-based positions do not describe the totality of ITE quality evaluation they do predominate. This paper identifies a tripartite heuristic for the identification of ITE epistemology that explicitly refers to, and is requiring of, ontological matters in the development of student teachers: identifying teaching, doing teaching, knowing teaching. Whilst it is the result of a Scottish project, Measuring the Quality of Initial Teacher Education (MQuITE), its emphasis is notable for other countries.
\end{abstract}

\section{Towards Initial Teacher Education quality}

Since the 1980s, higher education (HE) has been discussed in terms of the 'Evaluative State' (Neave, 1998). Based on market ideals, this seeks to reduce waste and ineffectiveness through the marshalling of managerialist and technicist methods and language (Neave, 1998). Whilst state-sponsored evaluation of HE institutional practice has always existed, the Evaluative State seeks to embed change-action. Prior to such alterations, university evaluation took the form of administrative verification, which sought to transcend change rather than meet it. Periodically commissions were called that attempted to meet periods of crisis (actual or perceived) but they were not necessarily systematised (Neave, 1998). The Evaluative State embedded matters such as the regulation of student access, curriculum content and internal governance (Neave, 1998) within system scrutiny and reform. 
Wrapped up here are principles which, taken together, provide for new thinking (Dill, 1998: 361):

- output as specified by centrally identified performance objectives;

- the delegation of authority over resource inputs and decisions to agencies; and,

- performance accountability thorough competition and privatisation.

Initial Teacher Education (ITE), embedded, as it is in many jurisdictions, in Higher Education Institutions (HEIs) is part of this. In many ways, however, ITE programmes speak to both the emancipatory (the development of teachers committed to social justice through the development of the self); and, the provision of labour and research for economic growth (Bleiklie, 1998). Whilst these two might seem different they are often not presented as such. Importantly, as Dall'Alba (2009) notes, within these frames professional education still tends to focus on knowledge and skills and such concentration fails to support professional transformation. In the latter position, the acts and actions of teaching become an end in themselves, rather than supports for ontological matters (cf. Barnett, 2009; Ennals, Fortune, Williams, \& D’Cruz, 2016; Sumsion \& Wong, 2011).

It can be argued that such ITE discussions are ontological and epistemological (e.g. Flores, 2001); they denote deliberation about the relationship 'self as teacher'; and, the means by which qualitative uplift can be maintained through skills and practices. Whether such epistemological/ontological distinctions are appropriate depends on whether one views the separation of epistemology and ontology as feasible or not. Knowledge development can, for example, effect one's self, and in this regard, a separation might be unhelpful. This said, it is clear that ITE, within the auspices of the Evaluative State, is often discussed in terms of teachers' epistemology.

...in most contemporary service occupations, professionalism, rather than being agreed from within, is being imposed from above and serves to promote and facilitate occupational change and as a disciplinary mechanism. (Edmond \& Hayler, 2013: 210)

Often, politically, ontological discussions are seemingly side-lined in the drive for economic uplift; moves to locate ITE as the development of craft knowledge and skills alone are well 
rehearsed the world over. However, many challenge such views (e.g. Menter, 2017). That apprenticeship models, drawing on matters of knowledge and skills predominantly, are neither sufficient nor desirable for developing teachers is a sentiment echoed across the sector.

Problematically, there is a concentration, in the minds of many policy-makers, that an increase in teacher knowledge and skills alone 'improves' education. For ITE, this is often couched in terms of student teachers being 'classroom ready' at the end of their 'education' or 'training'. What is globally evident is the desire to ensure that ITE is 'fit for purpose' (often in such terms). Accordingly, a plethora of mechanisms exist to ensure this such as inspections by agencies external to ITE programmes. Countries have their own mechanisms for quality assurance and control; for the most part, at the heart of such mechanisms lies the desire to ensure both the suitability and sustainability of ITE in terms of knowledge and skills. Whilst the academic community might discuss teacher ontology (e.g. Broadfoot \& Patricia, 1993; Bullough, 2005; Pike, 2003), this is not always explicit in policy pronouncements. A charitable reading might decide that ontological matters are actually part of policy and practice. However, this is often not evident and simplistic ways of judging quality ensue (Bleiklie, 1998), such as the number of students graduating with certain degrees or the number of hours spent learning key skills (such as literacy).

In counterpoint, there are rich writings on professional education which call for an examination of the ontological. Transformational professional education should, it is argued, develop ontological matters and so systematically challenge and change 'the self' (Dall'Alba, 2009). There has been much written on ontological matters (e.g. Andersson, 2010; Ennals, Fortune, Williams, \& D'Cruz, 2016; Sumsion \& Wong, 2011). Nevertheless, there is a need for professionals to develop suitable epistemologies. Knowledge and skills are important and to ignore this is to place the new teacher at considerable disadvantage. It is also clear that to assume this can be done with little or no regard to the ontological is problematic.

There is a need to examine ITE knowledge and skills might be located within both theory and the immediacy of practice. This paper examines this from a Scottish perspective. Whilst 
we argue for a recognition of the here-and-now, we also note the importance of enduring theoretical positions that permit international discussion. In examining epistemology we are explicit in our concern for the ontological: being, belonging and becoming a teacher as much as knowledge and skills. The paper outlines ways in which quality features as part of educational Discourse (Gee, 2012). We then consider what might be gained through the work of Biesta (2009) and 'good' education. Teacher quality is thus presented as part of the development of ontological discussions vis-à-vis professional, teacher education.

\section{The 'need' for quality}

It remains the case that, internationally, those with responsibility for system-wide reform desire ways to keep tabs on that which occurs. One matter is that of ITE-course evaluation and how this is gathered and deployed (or not). Whilst some might see professional-based self-assessment as fundamental, others might view this as akin to self-congratulation. On the latter, inspectorial-type systems favour distance between provider and audit, and establish criteria against which to judge that seek objectivity and distance. In such circumstances, the focus is on externally identifying matters that are of relevance to the judgement of ITE quality in order to prove quality; a focus on the observable and measurable. However, such systems are self-referential: they establish a method of conclusion-drawing that justifies the existence of the approach. The system's existence is justified through its own deployment. Such scrutiny might centre on examination of test scores of pupils of newly qualified teachers (cf. USA) or may rest on the quantification of ITE attributes through grading of teaching candidates (cf. England). Such endeavours seek an externally focused quality process: the assumption that professionals can be left alone to 'do the job' is challenged, replaced by mechanisms that 'hold to account' through 'rigorous' data gathering. Given this, it would seem propitious to discuss three things: how ITE might be conceived in such situations; how this might relate to notions of quality; and, how such interpretations might guide system-wide features.

Problematically, 'quality' is contested and problematic. At one level, ITE has qualities such as length of time to graduation, number of weeks spent in school, etc. All these hang together with the expected outcome 'the quality preparation of teachers'. In Scotland, the majority 
of the guidelines for ITE providers consist of statements about the duration of course etc. (GTCS (General Teaching Council Scotland), 2013). What is missed are questions about how these aspects fit together to describe, and hence allow evaluation of, quality ITE. 'Quality' is used variably and leads to a variable interpretations that, when applied, more or less, better or worse, describe features which can be taken as measures of 'quality ITE'. What should be of concern, though, are questions asked concerning ethical action, and how we identify and 'measure' this to describe success? While, at stake here, is quality in the normative sense, it is notable that policy often ends up describing quality.

For example, England, through the use of Ofsted inspections and government crafted standards, identifies Initial Teacher Training (ITT). Here training signifies provision oriented towards teaching as craft. Epistemological outcomes are positioned as most desirable. Indeed, in its White Paper, The importance of Teaching (Department for Education, 2010), this positon was clearly explicated (Author, 2011) [removed for the purposes of peer review]. ITT, located as it so often is in schools with reduced input for HEls, coupled with the aforementioned identification of training rather than education and the belief that teaching is a craft (Department for Education, 2010) demonstrates an ideological difference between that and ITE. ITT posits that learning teaching occurs through apprenticeship-type models:

We know that teachers learn best from other professionals and that an 'open classroom' culture is vital: observing teaching and being observed, having the opportunity to plan, prepare, reflect and teach with other teachers. Too little teacher training takes place on the job... (DfE, 2010: 19)

We will provide more opportunities for a larger proportion of trainees to learn on the job by improving and expanding the best of the current school-based routes into teaching - school-centred initial teaching training and the graduate teacher programme. (DfE, 2010: 23)

Indeed, the Carter Review (Carter, 2015: 14) of ITT in England posited that '[w]e would like applicants to understand that QTS [Qualified Teacher Status] is the essential component of ITT and that a PGCE is an optional academic qualification.' It appears then, that the main requisite for becoming a teacher in England is not 'qualification' but rather the achievement 
of government defined standards. This closely mirrors that which Author (2001) [removed for the purposes of peer review] notes as the drive in England for much of the last ten years: the elision of theory.

In Scotland, the preferred nomenclature has continued to be Initial Teacher Education (ITE). While the Scottish system uses standards to define ITE, the orientation is different. The ways in which ITE is positioned in Scotland, with its location in partnerships between institutes of higher education and schools, but with ultimate responsibility lying in the hands of the former, signifies an orientation that is professionalised and professionalising. At one level this is a matter of geography: school or university. However, it also requires certain questions to be asked such as: 'who am I?' and 'what do I want to become?' questions which form the heart of learning teaching (Mayer et al., 2017). It is, perhaps, that such questions are not the focus on ITT courses.

In Scotland, that the location for ITE is the Higher Education Institution (HEI) determines the ways in which quality is defined and identified. Indeed, there are many assurance (QA) mechanisms to 'robustly' ensure quality. Universities' quality frameworks are grounded in the quality code of the Quality Assurance Agency for Higher Education (UKSCQA UK Standing Committee for Quality Assessment, 2018). These encompass quality enhancement, quality assurance and academic standards. A key aim in developing this is to support public confidence in the quality of Higher Education. Further, ITE courses comply with institutionwide policies from Enhancement Led Institutional Review (QAA Scotland, 2012) annual reporting to the funding body, the Scottish Funding Council, to responding to student-issues raised at Programme Boards (the mechanisms by which student work and well-being is held up for scrutiny).

However, ITE, provides for an academic and professional qualification, and is subject to additional scrutiny by the General Teaching Council (Scotland) (GTCS, 2012) and Education Scotland (ES) (Education Scotland, 2018). The GTCS has a formal role in programme accreditation and validation and ES issues requests which involve the submission of information about ITE quality. In 2017, The Depute First Minister (DFM) requested that a self-evaluation framework be developed in conjunction with HEIs (Education Scotland, 
2018). It was established that aspects of ITE, not already evaluated by the HE framework would benefit. The focus was on ensuring that teachers could improve issues relating specifically to the school context such as Literacy, Numeracy, Health and Wellbeing and support further those with Additional Support Needs (ASN). It is anticipated that such calls will change, year on year, as new initiatives are introduced. What is notable here is that in Scotland, ITE quality is identified via partnership arrangements between government agencies, schools and universities. There are no 'external inspections'; rather data is gathered as part of the day-to-day drive to improve. This framework (Education Scotland, 2018) acknowledges, for example, that HEl partnerships need to look inwards, outwards and forwards when establishing for quality. ${ }^{1}$

\section{Quality matters}

The Evaluative State requires the evaluation of higher education quality and in this regard Scotland is no different. What drives this is the use of quantifiable data that can be displayed and interrogated. How this occurs is variable, but in essence consists of the use of defined indicators. There exist, for example, UK, whole-sector-wide measures used to determine quality which do not attune to the QA mechanisms above. For example, the National Student Survey (NSS, 2019) drives university league tables, as well as new measures such as the Teaching Excellence Framework (Office for Students, 2019).

What ensues is the orientation of discussions about quality against predefined outcomes, such as standards and representative alignment with such outcomes becomes all pervasive. Hence, the ways in which students judge 'satisfaction' on a course (cf. NSS) becomes a measure against which to judge the quality of the course. Problematically, there is assumed to be a causal link between, and an understanding that, the 'grade' accurately represents quality teacher preparation and exhibition. The numbers assigned to courses become the driving force in determining the quality of teacher preparation.

\footnotetext{
${ }^{1}$ For further information on ITE in Scotland, see: GTCS (General Teaching Council Scotland) (2013;); (GTCS (General Teaching Council Scotland) (2012); Education Scotland (2018).
} 
Following this, certain behaviours, such as working to standards occurs; as Gunzenhauser (2010) notes though, such judgements lead to the eliding of philosophies of education which should otherwise take centre stage. Here fallibility occurs due to the ways in which numbers, indicate the strength of provision: course $X$ has higher results than course $Y$ and is therefore better. What is seldom questioned is what better might be or what it might refer to, over and above the grade. Indeed, what is assumed is that the numbers tell us facts; an objective way to apportion and determine worth. What is missed is the relationship between various social, cultural and political matters. It is here that taken-for-granted assumptions underpinning the use of numeric referents becomes transformed into something that marks out quality as objective fact. The snapshot taken by grading becomes, ultimately truthful in that it seems, objectively, to define the merit, or otherwise, of the student and/or hosting institution. The world, identified 'as it is' and 'how it should be' (after Blackburn, 2006), is ignored in favour of a position that is simplistically defined.

Such a position rests on two assumptions: there is something underpinning quality teacher preparation that can be identified and measured; and, measures accurately do this measuring. It is not that the measures themselves are good or bad, but rather that towards which they are put. However, such attribution of number with worth is merely the reflection of a local position; measures for the here-and-now, defined by certain ways of viewing the world. They do not carry immutable truth, instead they define quality for the tasks of evaluating locally. Although believed to be 'objectively truthful', they are, in fact, justification: a 'social phenomenon' rather than a transaction between a 'knowing subject' and 'reality'.

Certainly there are measures such as course league tables that purport to measure elements such as degree classification, or student happiness. That quality is determined in such terms gives rise to the belief that data correctly identifies quality. Quality for and of ITE can, though, be defined variously, and is subject to multiple policy missives. Despite protestations to the contrary, policy decrees often place virtue on aspects of professional 
deliberations such as skills and knowledge. This might be considered attempts to describe teaching as interchange between various matters that appeal to that which seemingly is: that which can be observed. These call on the various ways in which teaching can be lauded. At its heart, then, debates about ITE are political matters, they are Discourses (Gee, 2012: 152 ), or '...distinctive ways of speaking/listening...so as to enact specific socially recognizable identities engaged in specific socially recognizable activities.' Teachers are subject to and construct such Discourses throughout their personal and professional lives. What is prevalent though is the local: the definition 'teacher' for the purposes of the here-and-now. This interplay imbues teaching with its ability to function in and on society. Epistemological positons lead to an intricate web for professional life.

Certainly, in Scotland, there are aspects of audit culture that prevail and standards form the cornerstone of ITE. The Evaluative State is writ large due, in part, to Scotland's membership of the UK, but also due to the fact that certain neoliberal matters have become part of the Scottish-HEl world.

However, there is a need to identify the ways teacher knowledge can be explained with reference to the ways in which this impacts the ontological. To this end, we here propose three aspects of 'learning teaching' (Mayer et al., 2017): identifying teaching; doing teaching; and, knowing teaching. Such epistemological matters, we argue, provide a foundation for ITE quality that explicitly acknowledges the ontological.

\section{'Identifying' teaching}

As Hargreaves (1988) notes, quality markers of teaching and, ergo, ITE have often rested on mechanisms that define professional access. Such entry characteristics signal the ways in which professionals are credentialed. Through mechanisms such as standards, entry and practice requirements, professional control is maintained. Associated guidance places much faith in transparency and objectivity. There are pressures to admit the 'right' individuals, defined in terms of their ability to gain from ITE based on assumptions and knowledge about 
how teachers learn and develop. There is, then, an element of identifying in terms of initial entry, progression through and exit from, ITE. As Dall'Alba (2009) notes, such positions carry weight in most professions: some sort of methods of acceptance onto professional courses, period of initial education and an induction period is often the norm. Whether this is because there is tried and tested knowledge about those who will and will not succeed and therefore entry is tightly controlled, or whether this is because of a form of hierarchical patronage is never really clear: most would argue for the former and against the latter we suspect.

Two positions are implied here: first there are features of being a teacher that are visible in only some; identifying this is part of the selection process. Second, ITE is time limited and only those who can muster the required attributes to pass in the given timeframe will benefit. Specific forms of knowing give rise to specific forms of allowing for entry. The positions are determined by Discourses (Gee, 2012) that are, in turn, determined by and determine the whole profession. In this regard by identifying and being identified, one must 'look and act' and be conscious of 'looking and acting' like a teacher.

Such exigencies, however, say more about the appropriation of particular Discourses than they do about particular teaching aspects. Such Discourses are part-and-parcel of identifying and require examination: this

actually results from processes of a social nature, from teachers actively interpreting, making sense of, and adjusting to, the demands and requirements their conditions of work place upon them. (Hargreaves, 1988: 211)

Access to, and success in, ITE is judged as a process of responses to occupational demands; but such matters operate within situational constraints: political, social, cultural and historical for example. Ignoring such constraints is problematic for these Discourses position teachers and teaching. For the entrant they are most acute when trying to understand acts 
and action given the lack of experience which often accompanies ITE entrants. Whilst teaching is certainly a matter of competence,

...it is competence of a particular kind. It is the competence to recognize and enact the rules, procedures and forms of understanding of a particular cultural environment. What is involved is not technical competence to operate in a pregiven, professionally correct and educationally worthwhile way, but cultural competence to 'read' and 'pass' in a system with its own specific history, a system once devised and developed to meet a very particular set of social purposes. (Hargreaves, 1988: 217)

By identifying with and to the profession with its written and unwritten rules, ITE students work within these to varying degrees; entry, progression and exit are governed by Discourses which offer positions for individuals to take up, resist or amend (Harré, 2004). Professionals have a history, a culture and learning; to engage with these is pre-requisite to becoming a professional (Dall'Alba, 2009).

However, Dall'Alba (2009) notes contradictions: the way we are subject to both continuity and change, possibilities and constraints. The teaching profession is not immutable; there are instances where entrants shake up the system. Indeed, when marked as for example, creativity, such resistance or amendment garners praise and recognition. It would seem, then, that identification is not as simple as it might be.

\section{'Doing' teaching}

Teaching is social: to be a teacher is to be in the world with others and act on the world for others. Teachers do things. They organise, they instruct, they embolden, they chastise. To be a teacher is to enter into discourse, or "...stretches of language which "hang together" so as to make sense to some community of people, such as a contribution to a conversation or a story' (Gee, 2012: 112). The discursive act defines the ways and means by which sense making occurs through moment-by-moment events. Through interactions with children, 
young people, other students, colleagues, the student-teacher acts on and in her environment; she invites others into her world and is permitted entry into the world of others. By doing, the student teacher engages in the world and on the world in order to gain entry into an aspect of the world (the profession).

In this way ITE must, then, deal with the ways in which categorisation plays a large part in the formation of professional identifying and doing. Hargreaves (1988) suggests that inculcation into teaching is governed by bounded categorisations such as subject or age range. For example, being a student teacher is learning the pedagogy and not pedagogy of one's profession. The Early Years professional orients his work through categorisations that define him (identifying) and his acts (doing) while working with young children. Commitment is thus as much about commitment to a set of principles that weaken some relationships as it is about those that reinforce others. Such matters are played out in the ways student teachers are positioned within the school and wider society giving rise to elevated or reduced commitment.

Further, teachers are often judged by factors said to depict effectiveness, such as noise levels or examination results. Even though student teachers often have mentors who observe and guide their work, the features that mark out the successful student teacher are governed by mechanisms that are in the here-and-now: subjective interpretations for quality. It could be argued that matters such as standards for ITE (cf. GTCS, 2012) play a role here in attempting to guide the judgement of student teachers' and all that imbues in terms of judgements about teaching quality. Problematically, standards make us 'see' as a certain type of person. Supervisors and students are governed by Discourses of competence; they act in ways coterminous with these in order to be seen as a particular type of subject (Ortlipp, 2009). Much has been written here on performativity and the way it constructs the subject (e.g. Ball, 2003). Doing, then, is governed by much more than a simple interpretation of the observable against pre-existing categorisations for judgement. 


\section{'Knowing' teaching}

Such matters imbue with often fleeting meaning; certain knowledge forms construct pedagogical and educational notions. In effect, though, what is resonant and redolent 'here', may not be so 'there'. For the student teacher this is worrisome; how can they be prepared to work in schools if theoretical matters are not always easily transferrable (Allen, Ambrosetti, \& Turner, 2013; Grudnoff, 2011). Indeed, for ITE this is problematic. Student teachers and newly qualified teachers are not reticent in stating that theory is sometimes found wanting in the classroom (Roth, 2002). However, what is meant by this? It is, surely, not the case that theory has no place in beginning teaching; if true, then we could extrapolate to the rest of the profession. Whilst this may reflect part of the Discourse of some governments, these calls are overtly political for practicality. What we mean here is that positioning teaching as theory-free marks out a simplistic policy to cheapen and quicken teacher preparation. It exercises a mechanism for the purposing of political position. Following this, the student teacher, whilst announcing that theory does not help, is, in fact, an agent of her own downfall for such posturing is a theoretical position. When the student teacher bemoans that theory does not help, we need to look for other explanations as to why they might or might not be right.

Here, we can turn to praxis (Roth, 2002). Whilst identifying and doing teaching, student teachers engage with a wealth of knowledge about what is before them. In turn they position themselves in relation to such knowing: the language they encounter and bring to the situation, and inherent storylines offer positions for them to take up, resist or amend (cf. Harré, 2004). Part of this is the knowing they can bring to bear. By positioning they come to see the world in ever shifting and temporal moments that convey meaning. In this regard that which has been learnt theoretically might or might not be called to action. This can be explained through a simple example: classroom management. The ways in which this is taught in universities does not always resonate (Roth, 2002). This is not the fault of theory; rather this is a manifestation of the context in which the theory is put to use (or not). It cannot be said that theory does not matter because it does not work in this context, for theory is not infallible. The issue here is not theory, it is an issue that rests in the relationship between student and context. What is at stake is the creation of local 
theoretical positions, through praxis, that enable the student to orient her work meaningfully. The here-and-now of the particular requires the conjoining of personally held understandings and social, cultural, political manifestations. Such theory-making happens in schools, in classrooms, in relationships. It is inextricable tied to practice; it is praxis lived.

Notably, such positions might well call for ITE to occur in schools alone. This is problematic for at least three reasons. First, the generation of local praxis alone can close professional experience, that is, it develops knowledge that is not both context-specific and contextbound. Second, theories about, for example, controlling a class, have roots in matters other than just, presentation, voice, etc. They are part of the web of theory expressed through discussions about poverty, ethnicity, gender, etc., i.e., Discourses. Third, education provision that is based solely on praxis has the potential to be mere whimsy or ideology.

To return to the student who does not value theory. Here, probably, what we see is a misunderstanding of the ways in which theory helps. It may well be that race-theory, or social constructivist ideas are not 'held in the moment', but what these form are ways of living with meaning and intent: they call for reflection in/on praxis; consideration of the ways in which locally formed praxis is expressive of wider educative moments. They are not before or after praxis, they are with praxis: they garnish personal construction.

\section{Towards 'learning teaching'}

Whilst doing, knowing and identifying teaching, one is, ontologically, becoming a teacher, being a teacher and belonging to teaching. In the moment-by-moment environment of the classroom certain positions are taken up, modified or resisted (cf. Harré, 2004) as discourse unfolds. But this means more than simply being present in the world, it also means knowing and being present on the world; acting in such a way as to effect change that alters the taught, the teacher and that to be considered. Here, then, is the realm of the reflective practitioner reflecting on and in practice, or who uses Spielraum (room for manoeuvre) perhaps (Roth, 2002) to engage in thought cognisant of alterations to oneself and others. 
Educating for these requires reflection on 'who am I', and 'Who am I in relation to this other I am teaching?' As Dall'Alba (2009: 37) states

[t]his trans-formation of the self can be achieved by interrogating what we take for granted about our world and ourselves; by challenging assumptions we make about them and have historically made.

By changing the orientation for knowing, doing and identifying, one appreciates different ways of being. 'Through interrogating and re-shaping assumptions about what it means to teach ... new ways of being are opened to aspiring professionals and can begin to take shape' (Dall'Alba, 2009: 37). We are entwined in the world. Thus, acceptance into the guild preordains us and locates us as beings with externally given purpose: to identify, know and act, one must belong, be and become but with room to challenge.

\section{'Good' quality}

Here we can consider Biesta's (2009) 'good education'. For Biesta, part of education involves credentialing features with examinations, etc. that mark out success. In this regard, ITE is a means of entry into the profession whereby students can become part of the social order. Notable here are the ways in which teachers should and do act; in some respects these are not always the same and thus is the second feature, socialisation: the process of entering the profession. Socialisation and qualification orient both the work of the individual and the life of the profession. They feature as markers of professionality: the ways in which individuals express their professionalism through praxis. It is clear, though, that one can exist outside of this. Whilst such positions can take their toll (in terms of burn out, stress, etc.) out of such challenges can also come progress and growth, and it is for this reason that the teacher as individual subject needs to be nurtured. A process of Subjectification ensues; 'processes of individuation or...processes of Subjectification - of becoming a subject...It is precisely not about the insertion of 'newcomers' into existing orders, but about ways of being that hint at independence from such orders...' (Biesta, 2009, 40). While socialisation and qualification allow entry, it is Subjectification which widens the frame so the student might embark ontologically. 
Following on, it is clear that enculturation into the existing field of teaching is a worthwhile endeavour and one which rightly takes up time and space on ITE programmes. After all, matters such as, for example, modes of speech are mechanisms by which people are admitted to the profession in varying degrees and are able to mark and be marked as teachers. Problematically, quality cannot simply be this for at times it is not entirely clear what is held as quality of ITE. Indeed, it is a contested term that in many instances defies definition. At its heart it has a dichotomous relationship: praxis for the here-and-now and theory for that which transcends context. In effect, what is presented as quality in, for and of ITE is dependent on factors that often exist outside of ITE itself. However, such meanings only provide clarity for the purposes of the here-and-now; their political dimension plays out. This brings us full circle in one respect: the need for language to specify the elements of quality. As stated above, definitions can only work in the here-and-now; they carry with them no ultimate pronouncement, no rational explanation for every quality situation. In effect, the positions adopted by language are performative; the adoption of key terms performs a specific function through which we can share understanding and meaning: acceptability is thus crafted. What is permissible in one context might not be permissible in another. Indeed, challenge might be forthcoming, challenge which incorporates attempts at defining alternative terms and provision. It is key, then, that terminology marks out both the purposes of measuring quality, but also discussion and debate.

\section{Conclusion}

What we have tried to do here is extend the realm of theorising about ITE and its relationship to 'quality'. It seems that what is needed are local solutions for local needs through the articulation of language that recognises the immediacy of teaching praxis and the enduring nature of educational theorising. By expressing ITE in terms of doing, identifying and knowing, ITE can be scrutinised in a way which recognises its relationship with the ontological. However, as politics the world over often mainly constructs teacher preparation and learning in terms of its epistemic qualities, there is a need to speak to this. In this regard, and by virtue of the fact that the work here seeks to strengthen ITE as part of the HEI venture, we have tried to signal ITE quality and quality ITE. In so doing, we have shown that such matters are explicitly ontological, but they also call on us as challenges to 
our epistemological underpinnings. Whilst we are clear that matters of the here-and-now orient practice and its relationship to theory, we are also clear that enduring theoretical positions play a part in ITE. Indeed, such aspects matter the world over.

\section{Funding}

This article forms part of the Measuring Quality in Initial Teacher Education project, funded by the Scottish Government.

\section{References}

Adams, P. (2011). (Dis)continuity and the Coalition: Primary pedagogy as craft and primary pedagogy as performance. Educational Review, 63(4), 467-483. https://doi.org/10.1080/00131911.2011.620699

Allen, J. M., Ambrosetti, A., \& Turner, D. (2013). How school and university supervising staff perceive the pre-service teacher education practicum: A comparative study. Australian Journal of Teacher Education, 38(4), 108-128. https://doi.org/10.14221/ajte.2013v38n4.9

Andersson, T. (2010). Struggles of managerial being and becoming: Experiences from managers' personal development training. Journal of Management Development, 29(2), 167-176. https://doi.org/10.1108/02621711011019305

Ball, S. J. (2003). The teacher's soul and the terrors of performativity. Journal of Education Policy, 18(2), 215-228. https://doi.org/10.1080/0268093022000043065

Barnett, R. (2009). Knowing and becoming in the higher education curriculum. Studies in Higher Education, 34(4), 429-440. https://doi.org/10.1080/03075070902771978

Biesta, G. (2009). Good education in an age of measurement: On the need to reconnect with the question of purpose in education. Educational Assessment, Evaluation and Accountability, 21(1), 33-46. https://doi.org/10.1007/s11092-008-9064-9

Bleiklie, I. (1998). Justifying the Evaluative State: New Public Management Ideals in Higher Education. Journal of Public Affairs Education, 4(2), 87-100. https://doi.org/10.1080/15236803.1998.12022016

Broadfoot, M., \& Patricia, O. (1993). Becoming and Being a Teacher: The Influence of the 
National Context. European Journal of Education, 28(1), 105-116.

Bullough, R. V. (2005). Being and becoming a mentor: School-based teacher educators and teacher educator identity. Teaching and Teacher Education, 21(2), 143-155. https://doi.org/10.1016/j.tate.2004.12.002

Carter, A. (2015). Carter Review of initial teacher training (ITT). Retrieved from https://www.gov.uk/government/publications/carter-review-of-initial-teacher-training

Dall'Alba, G. (2009). Learning professional ways of being: Ambiguities of becoming. Educational Philosophy and Theory, 41(1), 34-45. https://doi.org/10.1111/j.1469$5812.2008 .00475 . x$

Department for Education. (2010). The Importance of Teaching. The Importance of Teaching: The Schools White Paper 2010. London: Department for Educatiion. https://doi.org/10.2307/3333031

Dill, D. D. (1998). Evaluating the ' Evaluative State': Implications for Research in Higher Education. European Journal of Higher Education, 33(3), 361-377.

Edmond, N., \& Hayler, M. (2013). On either side of the teacher: Perspectives on professionalism in education. Journal of Education for Teaching, 39(2), 209-221. https://doi.org/10.1080/02607476.2013.765193

Education Scotland. (2018). Self-evaluation framework for Initial Teacher Education. Livingston: Education Scotland. Retrieved from https://education.gov.scot/improvement/Documents/SelfEvalFrameworkforlTEDec18. pdf

Ennals, P., Fortune, T., Williams, A., \& D’Cruz, K. (2016). Shifting occupational identity: doing, being, becoming and belonging in the academy. Higher Education Research and Development, 35(3), 433-446. https://doi.org/10.1080/07294360.2015.1107884

Flores, M. A. (2001). Person and context in becoming a new teacher. Journal of Education for Teaching, 27(2). https://doi.org/10.1080/02607470120067882

Grudnoff, L. (2011). Rethinking the practicum: Limitations and possibilities. Asia-Pacific Journal of Teacher Education, 39(3), 223-234. https://doi.org/10.1080/1359866X.2011.588308

GTCS (General Teaching Council Scotland). (2012). The Standards for Registration: mandatory requirements for Registration with the General Teaching Council for Scotland. Edinburgh: GTCS. https://doi.org/10.3837/tiis.2014.10.016 
GTCS (General Teaching Council Scotland). Guidelines for Initial Teacher Education Programmes in Scotland (2013). Retrieved from http://www.gtcs.org.uk/web/FILES/about-gtcs/guidelines-for-ite-programmes-inscotland.pdf

Gunzenhauser, M. G. (2010). Preparing for High-Stakes Testing. Theory Into Practice, 42(1), 51-58. https://doi.org/10.1207/s15430421tip4201

Hargreaves, A. (1988). Teaching quality: A sociological analysis. Journal of Curriculum Studies, 20(3), 211-231. https://doi.org/10.1080/0022027880200302

Harré, R. (2004). Positioning Theory. Retrieved from www.massey.ac.nz/ alock/virtual/positioning.doc,

Mayer, D., Dixon, M., Kline, J., Kostogriz, A., Moss, J., Rowan, L., ... White, S. (2017). Studying the Effectiveness of Teacher Education: Early Career Teachers in Diverse Settings. Studying the Effectiveness of Teacher Education: Early Career Teachers in Diverse Settings. https://doi.org/10.1007/978-981-10-3929-4

Menter, I. (2017). The role and contribution of higher education in contemporary teacher education. Retrieved from http://www.scde.ac.uk/wpcontent/uploads/2017/05/Report-lan-Menter-2017-05-25.pdf

Neave, G. (1998). The Evaluative State Reconsidered. European Journal of Education, 33(3), 265-284.

Ortlipp, M. (2009). Shaping conduct and bridling passions: Governing practicum supervisors' practice of assessment. Contemporary Issues in Early Childhood, 10(2), 156-167. https://doi.org/10.2304/ciec.2009.10.2.156

Pike, M. A. (2003). On being in english teaching: A time for heidegger? 1. International Journal of Phytoremediation, 21(1), 91-99. https://doi.org/10.1080/1358684032000055154

QAA Scotland. (2012). Enhancement-led Institutional Review Handbook, (April), 35. https://doi.org/10.1016/j.ijpe.2006.03.002

Sumsion, J., \& Wong, S. (2011). Interrogating "belonging" in belonging, being and becoming: The early years learning framework for Australia. Contemporary Issues in Early Childhood, 12(1), 28-45. https://doi.org/10.2304/ciec.2011.12.1.28

UKSCQA UK Standing Committee for Quality Assessment. (2018). The revised UK Quality Code for Higher Education, (March). Retrieved from www.ukscqa.org.uk. 
